J. Dairy Sci. 96:2925-2938

http://dx.doi.org/10.3168/jds.2012-6035

(C) American Dairy Science Association ${ }^{\circledR}$, 2013. Open access under CC BY-NC-ND license.

\title{
Prevalence of subclinical ketosis and relationships with postpartum diseases in European dairy cows
}

\author{
V. S. Suthar, ${ }^{*}$ J. Canelas-Raposo, $†$ A. Deniz, $†$ and W. Heuwieser*1 \\ ${ }^{*}$ Clinic for Animal Reproduction, Faculty of Veterinary Medicine, Freie Universität Berlin, Koenigsweg 65, 14163 Berlin, Germany \\ †Bayer HealthCare Animal Health, Alfred-Nobel-Strasse 50, 40789 Monheim, Germany
}

\begin{abstract}
Subclinical ketosis (SCK) is defined as concentrations of $\beta$-hydroxybutyrate (BHBA) $\geq 1.2$ to $1.4 \mathrm{mmol} / \mathrm{L}$ and it is considered a gateway condition for other metabolic and infectious disorders such as metritis, mastitis, clinical ketosis, and displaced abomasum. Reported prevalence rates range from 6.9 to $43 \%$ in the first 2 mo of lactation. However, there is a dearth of information on prevalence rates considering the diversity of European dairy farms. The objectives of this study were to (1) determine prevalence of SCK, (2) identify thresholds of BHBA, and (3) study their relationships with postpartum metritis, clinical ketosis, displaced abomasum, lameness, and mastitis in European dairy farms. From May to October 2011, a convenience sample of 528 dairy herds from Croatia, Germany, Hungary, Italy, Poland, Portugal, Serbia, Slovenia, Spain, and Turkey was studied. $\beta$-Hydroxybutyrate levels were measured in 5,884 cows with a handheld meter within 2 to $15 \mathrm{~d}$ in milk (DIM). On average, 11 cows were enrolled per farm and relevant information (e.g., DIM, postpartum diseases, herd size) was recorded. Using receiver operator characteristic curve analyses, blood BHBA thresholds were determined for the occurrence of metritis, mastitis, clinical ketosis, displaced abomasum, and lameness. Multivariate binary logistic regression models were built for each disease, considering cow as the experimental unit and herd as a random effect. Overall prevalence of SCK (i.e., blood BHBA $\geq 1.2 \mathrm{mmol} / \mathrm{L}$ ) within 10 countries was $21.8 \%$, ranging from 11.2 to $36.6 \%$. Cows with SCK had 1.5, 9.5, and 5.0 times greater odds of developing metritis, clinical ketosis, and displaced abomasum, respectively. Multivariate binary logistic regression models demonstrated that cows with blood BHBA levels of $\geq 1.4, \geq 1.1$ and $\geq 1.7 \mathrm{mmol} / \mathrm{L}$ during 2 to 15 DIM had 1.7, 10.5, and 6.9 times greater odds of developing metritis, clinical ketosis, and displaced abomasum, respectively, compared with cows with lower
\end{abstract}

Received August 6, 2012.

Accepted January 9, 2013.

${ }^{1}$ Corresponding author: w.heuwieser@fu-berlin.de
BHBA blood levels. Interestingly, a postpartum blood BHBA threshold $\geq 1.1 \mathrm{mmol} / \mathrm{L}$ increased the odds for lameness in dairy cows 1.8 (95\% confidence interval: 1.3 to 2.5) times. Overall, prevalence of SCK was high between 2 to 15 DIM and SCK increased the odds of metritis, clinical ketosis, lameness, and displaced abomasum in European dairy herds.

Key words: prevalence, subclinical ketosis, $\beta$-hydroxybutyrate, postpartum disease

\section{INTRODUCTION}

It is well known that severe negative energy balance (NEB) in the periparturient period increases the risk for postpartum diseases such as retained placenta (RP), milk fever, metritis, mastitis, clinical ketosis (CK), and displaced abomasum (DA; Dohoo et al., 1983; Duffield et al., 2009; LeBlanc, 2010). Several epidemiological studies have demonstrated that these diseases cause major financial losses by increasing diagnosis and treatment costs and decreasing milk yield and reproductive performance in dairy herds. Approximately $75 \%$ of diseases in dairy cattle occur in the first month postpartum (LeBlanc, 2010) and 50\% of dairy cattle suffer from metabolic and infectious diseases in the transition period (LeBlanc, 2010). Therefore, the potential of early diagnostic approaches (i.e., rectal temperature, vaginal discharge, rumen motility, blood, urine or milk ketone bodies, rumen auscultation, and percussion) for these diseases has been researched in several clinical and epidemiological studies (Dohoo and Martin, 1984; Oetzel, 2004; LeBlanc, 2010).

The severity and duration of NEB is reflected by the increase in circulating NEFA and BHBA and the degree of decrease in glucose concentrations (Drackley, 1999). The decreased DMI prepartum causes NEB and increases NEFA and BHBA concentrations (Suriyasathaporn et al., 1999; LeBlanc, 2010; Gumen et al., 2011). The case definition of subclinical ketosis (SCK) is characterized by serum BHBA levels $>1.0$ to $1.4 \mathrm{mmol} / \mathrm{L}$ in the absence of clinical signs of ketosis (Duffield et al., 1998; Iwersen et al., 2009; Rollin et al., 2010). The highest incidence of SCK occurs within the 
first 1 to $3 \mathrm{wk}$ of lactation (Oetzel, 2004; Duffield et al., 2009). Most recently, McArt et al. (2012) reported an average SCK incidence of $43 \%$ (ranging from 26 to $56 \%)$ and described that the peak incidence $(28.9 \%)$ occurred at 5 DIM. Cows from 4 dairy herds (2 in New York and 2 in Wisconsin) were each tested for SCK 6 times at $3,4,5,14,15$, and 16 DIM. It is plausible that a more frequent measuring protocol initiated early postpartum increases the observed incidence of SCK and shifts the time of observed peak incidence to earlier in lactation.

Reported prevalence rates range from 8.9 to $43 \%$ in the first 2 mo of lactation (Dohoo et al., 1983; Duffield et al., 1998; McArt et al., 2012). Subclinical ketosis is a risk factor for subsequent diseases and has been associated with metritis, cystic ovarian disease, CK, and DA. It has been demonstrated that BHBA concentrations exceeding thresholds of 1.1 and $1.6 \mathrm{mmol} / \mathrm{L}$ during first 2 wk after calving were associated with a decreased probability of pregnancy and an increased culling risk, respectively (Walsh et al., 2007; Duffield et al., 2009; Roberts et al., 2012). Odds of developing DA, CK, and metritis were 2.6 to 8.0, 3.0 to 6.0 , and 1.0 to 5.8 higher, respectively, for cows exceeding BHBA concentrations of 1.2 to $1.4 \mathrm{mmol} / \mathrm{L}$ during the first 2 wk after calving (Geishauser et al., 1998; Duffield et al., 2009; Dubuc et al., 2010). Chapinal et al. (2012) demonstrated that serum BHBA $\geq 1.4$ and $\geq 1.2 \mathrm{mmol} / \mathrm{L}$ during the first and second weeks after calving, respectively, were associated with considerable milk losses (1.5 to $2.4 \mathrm{~kg}$ ).

Hoeben et al. (1999) and Suriyasathaporn et al. (1999) demonstrated in their in vitro studies that severe NEB or direct effects of ketones on neutrophils are a likely risk factor for postpartum infectious diseases such as metritis and mastitis. Therefore, testing for SCK during the first 2 wk of lactation could be beneficial (Geishauser et al., 1998; Iwersen et al., 2009; LeBlanc, 2010). The gold standard test for SCK is blood BHBA, because it is more stable in blood than acetone or acetoacetate (Oetzel, 2004). Recently, an electronic BHBA handheld meter (Precision Xtra, Abbott Diabetes Care, Abingdon, UK) has been validated for determination of BHBA from whole blood in dairy cows (Iwersen et al., 2009). Considering thresholds of 1.2 and $1.4 \mathrm{mmol} / \mathrm{L}$, the sensitivity and specificity of determining SCK were 88 to $96 \%$ and 96 to $97 \%$, respectively. Most studies reporting prevalence rates for SCK and its association with postpartum infectious and metabolic diseases have been conducted in North America. The participating research herds included were from Ontario, Canada (LeBlanc et al. 2005; Duffield et al., 2009) or New York, Pennsylvania, and Vermont in the United States (Ospina et al., 2010). These studies reported cowlevel associations of BHBA with health and produc- tion. Only one study (Chapinal et al., 2011) described relationships of selected metabolite concentrations with diseases in early lactation considering different management systems across 4 regions including the Northeast (New York, Ontario), Midwest (Minnesota, Wisconsin), Southeast (Florida, Georgia, North Carolina, South Carolina, Virginia), and West (California) of North America. There is a dearth of information on prevalence of SCK and its association with postpartum diseases considering a wider geographical area and more diverse dairy herds, particularly outside North America. Therefore, the objectives of this study were to (1) determine prevalence of SCK, (2) identify optimum thresholds of blood BHBA measured 2 to 15 DIM, and (3) study their relationships with the postpartum-related diseases metritis, mastitis, CK, DA, and lameness in European dairy farms.

\section{MATERIALS AND METHODS}

From May to October 2011, a convenience (nonrandom) sample of 593 dairy herds located across Croatia, Germany, Hungary, Italy, Poland, Portugal, Serbia, Slovenia, Spain, and Turkey was studied. The number of cows per herd and daily average milk production per herd varied from 70 to 2,000 and from 17.5 to 34 $\mathrm{kg} / \mathrm{d}$, respectively. In this study, $98 \%$ of the herds kept Holstein-Friesian cows, $1.2 \%$ kept Holstein-Friesian crossbreed, and $0.8 \%$ kept Jersey, Brown Swiss, other, and crossbreeds of those. Efforts were made to standardize data collection for participating dairy farms. Veterinarians were selected by the technical service personnel from Bayer Animal Health (Leverkusen, Germany) and received the same documentation consisting of standardized forms to obtain informed consent, to collect relevant farm data, and to provide a list with definitions of diseases of interest. All veterinarians consented to participate, and the study was approved by the Institutional Animal Care and Use Committee of Freie Universität Berlin, Germany.

A veterinarian selected the herds at his or her own discretion. For consistency, the disease definitions of RP (farm personnel diagnosis of failure to pass the fetal membranes within $24 \mathrm{~h}$ after calving; Duffield et al., 1998; LeBlanc et al., 2002); milk fever (farm personnel or veterinarian diagnosis of stage II or III hypocalcemic parturient paresis; Cook et al., 2006); clinical mastitis (recorded one or more quarter with visually abnormal milk within 30 DIM); metritis (veterinary diagnosis based on systemic illness attributed to fetid uterine infection before 15 DIM; Duffield et al., 1998); CK (veterinary diagnosis of primary CK based on complaint of inappetence or decreased milk production within 30 DIM, presence of a positive urine or milk ketone 
test, and absence of a DA or other primary disease; LeBlanc et al., 2002); DA (veterinary diagnosis of a left or right side displacement of the abomasum within 30 DIM based on auscultation of a characteristic "ping"; generally confirmed at surgery; Duffield et al., 1998; LeBlanc et al., 2002); and lameness (producer diagnosis of undifferentiated lameness within 30 DIM based on an abnormal gait or lack of weight bearing on a limb; includes diagnosis of interdigital and digital dermatitis; Cook et al., 2006) were supplied to the veterinarians on information sheets. Veterinarians educated herd managers through verbal communication and the information sheets on case definitions of disease events to standardize the information collected. The disease information was collected by use of recorded disease events on a standard form, on-farm diaries, computerrecorded events, veterinary visit summaries, and weekly visit of the assigned veterinarian.

Cows and heifers were enrolled beginning $10 \mathrm{~d}$ before expected calving date using a list generated from herd management software programs, farm diaries, and registers. After calving, blood BHBA concentration $(\mathrm{mmol} / \mathrm{L})$ was measured using a handheld meter (Precision Xtra) in whole blood (Iwersen et al., 2009), and information such as herd milk yield $(\mathrm{kg} / \mathrm{d})$ and herd size were documented. Farm personnel were instructed to document any incident of dystocia, twins, RP, milk fever, metritis, mastitis, CK, DA, and lameness. Because of a lack in the consistency of recording, twins and dystocia were removed from analyses. Prevalence of SCK was estimated considering a blood BHBA threshold of $\geq 1.2 \mathrm{mmol} / \mathrm{L}$ (Rollin et al., 2010).

\section{Sample Size}

In the present study, a convenience sample of herds was utilized as has been done in other studies (Duffield et al., 2009; Ospina et al., 2010; Chapinal et al., 2011). Initially, we planned random selection of 12 cows per herd (Dohoo et al., 2009); however, after removing erroneous data because of logistic limitations, a mean sample size of 11 cows per herd and a minimum of 280 cows per country resulted, which is in line with recommendations by Willer (1982). According to Borchardt and Staufenbiel (2012), this sample size is also adequate for use with variables that have a normal distribution or moderate skewness when evaluating the deviation of a sample mean from the healthy population mean. In this study, a sample size of 11 cows per herd provides a moderate risk for type $\mathrm{I}(\alpha=0.1)$ and a marginal risk for type II error $(\beta=0.024)$ in herd testing for metabolic variables.

\section{Inclusion Criteria}

Data records of cows were excluded from study if blood BHBA concentration was measured before 1 or after 15 DIM. Cows with missing records were excluded.

\section{Statistical Analyses}

All analyses were performed with MedCalc (version 12.0.3.0, Schoonjans, Mariakerke, Belgium) and SPSS (version 19.0, IBM Inc., IBM-Allee, Ehningen, Germany). Incidence of postpartum diseases, including RP, milk fever, metritis, mastitis, CK, DA and lameness, and prevalence rate of SCK from 2 to 15 DIM, were entered into Excel (Microsoft Corp., Redmond, WA) spreadsheets dichotomized (i.e., $0=$ without disease, $1=$ with disease). Frequencies of occurrences are presented to demonstrate descriptive statistics on categorical data.

The concentration of blood BHBA was the main risk factor of interest in the assessment of the development of postpartum diseases. At this level of analyses, the blood BHBA concentrations are presented as continuous variables. Furthermore, incremental $0.1 \mathrm{mmol} / \mathrm{L}$ cutpoints of BHBA from 0.6 to $2.0 \mathrm{mmol} / \mathrm{L}$ were evaluated using dichotomous variables (i.e., 0 for samples below a certain cutpoint, 1 for samples above a certain cutpoint). All 15 thresholds were evaluated with the occurrence of metritis, mastitis, CK, DA, and lameness in a univariate binary logistic regression.

To identify optimum thresholds of blood BHBA concentration $(\mathrm{mmol} / \mathrm{L})$ for the occurrence of postpartum diseases as specified (Table 1), we performed receiver operator characteristic (ROC) analyses. The ROC curves analyze sensitivity and 1 - specificity. Sensitivity is the proportion of animals diagnosed with a specified disease that is above an optimum threshold, and specificity is the proportion of animals that did not have the disease that was below a given threshold (Greiner et al., 2000). The point in an ROC curve that is closest to the upper left corner has the highest combined sensitivity and 1 - specificity (i.e., Youden index) and is considered the optimum threshold for that particular postpartum disease. Interpretation of this optimum threshold was based on the area under the curve (AUC). If the $\mathrm{AUC}=0.5$, it was considered noninformative; if $0.5<\mathrm{AUC} \leq 0.7$, it was accurate; if $0.7<\mathrm{AUC} \leq 0.9$, it was very accurate; if $0.9<\mathrm{AUC}$ $<1$, it was highly accurate; and if $\mathrm{AUC}=1$, then it was considered perfect (Swets, 1988). Likelihood ratios $[(\mathbf{L R}) ;=$ sensitivity $/(1$ - specificity $)]$ were calculated to describe the probability of an animal subsequently diagnosed with the postpartum disease of interest hav- 
ing a test result at or above a given cutpoint compared with a similar result in an unaffected animal. The LR positive $(\mathrm{LR}+)$ was the probability that a test result at or above the threshold would be more likely to come from an animal later diagnosed with the disease.

Univariable binary logistic regression models were used to screen the potential cow-level covariates including SCK, disease-specific optimum thresholds of BHBA, parity (1, 2, 3, and $\geq 4$ ), months (May to October 2011), country (Croatia, Germany, Hungary, Italy, Poland, Portugal, Serbia, Slovenia, Spain, and Turkey), RP, milk fever, and diseases that occurred before the disease of interest for their association with the 5 individual diseases (i.e., metritis, mastitis, CK, DA, lameness). Our data set lacked information on DIM of first metritis occurrence. At the same time, inclusion of metritis in observational studies for disease prediction is challenging because of diagnostic difficulties (Sheldon et al., 2006; Dubuc et al., 2010), limited follow-up (Duffield et al., 2009; Ospina et al., 2010), misclassification with RP (Sheldon et al., 2006; Ospina et al., 2010), and subjective variation (Sheldon et al., 2006; Chapinal et al., 2011). Therefore, in this study, overall incidence of metritis was offered to the SCK and other disease models. For all disease analyses, data were arranged such that only data for which blood BHBA measured 1 $\mathrm{d}$ before the disease diagnosis (except metritis) were included (Duffield et al., 2009). The interaction between potential covariates for the respective diseases was also evaluated. The influence of potential interactions on disease of interest $(P<0.10)$ was not determined in the univariate logistic model and was removed from further analyses.

Variables with $P<0.10$ in the initial screening were submitted to multivariate binary logistic regression models which were built in GENLINMIXED procedure of SPSS. Manual backward stepwise elimination procedure was used to eliminate variables from the model. Any variable with a significance level of $P \leq 0.05$ was retained in the model. Considering cow as the experimental unit and herd as a random effect, the diseasespecific screened variables were included in the models. Statistical significance was assessed at $P \leq 0.05$. The scope of this study was to evaluate association of SCK, disease-specific optimum thresholds of blood BHBA, and their odds of subsequent developing clinical diseases. Therefore, multivariate logistic regression models for each clinical disease were built considering SCK and disease-specific optimum thresholds separately.

\section{RESULTS}

Overall, 6,872 cows from 593 farms were initially enrolled (mean: 12; median 8, minimum: 7; maximum:

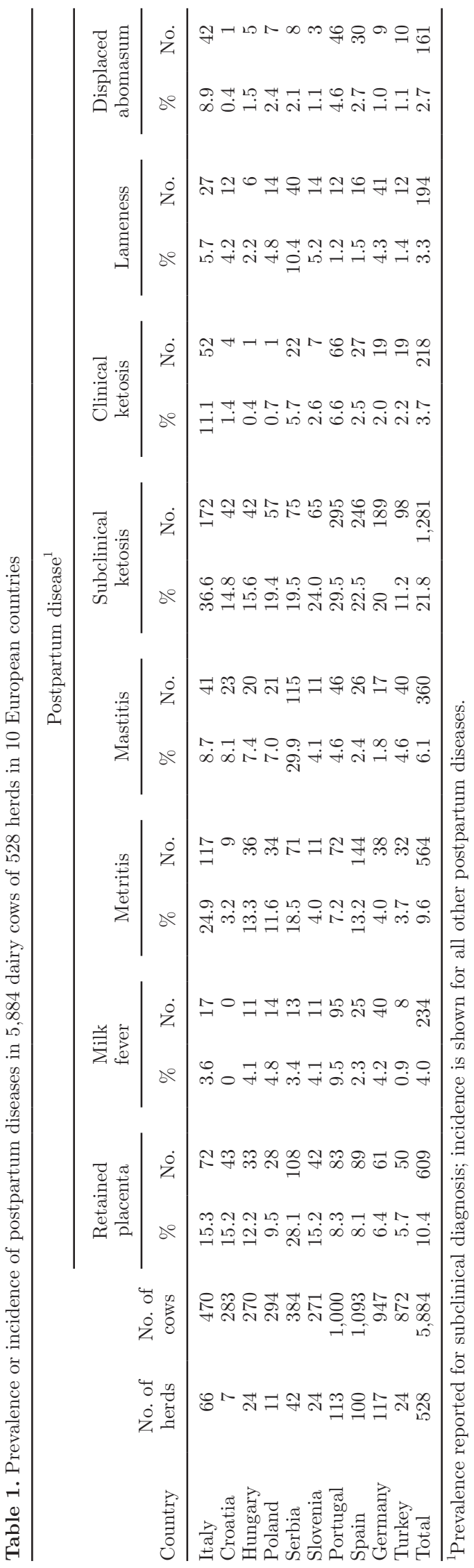


377 cows/farm). After excluding 988 cows (14.4\%) and 65 herds, a total of 5,884 records from 528 herds of 10 countries were used for the final analyses. Reasons for excluding 10.7 and $3.7 \%$ cows (total $14.4 \%$ ) from analyses were incorrect timing of blood BHBA measurement and missing information, respectively. For final SCK, metritis, mastitis, CK, lameness, and DA models, 843, $847,843,861,843$, and 472 cows were excluded, respectively, due to a disease event before blood BHBA measurement.

Incidence of postpartum diseases including RP, milk fever, metritis, mastitis, CK, DA, and lameness and the percentage prevalence of SCK by 2 to 15 DIM is reported in Table1. The univariate association and detailed test characteristics (i.e., predictive positive and negative values, $\mathrm{LR}+$, and sensitivity and specificity of serial thresholds of BHBA from 0.6 to $2.0 \mathrm{mmol} / \mathrm{L}$ with clinical diseases) are demonstrated in Table 2. Univariate models of serial threshold from 0.6 to $2.0 \mathrm{mmol} / \mathrm{L}$ of BHBA did not reveal a relationship with mastitis $(P$ $<0.1$; data not shown). Optimum BHBA thresholds of $\geq 1.1, \geq 1.4, \geq 1.7$, and $\geq 1.1 \mathrm{mmol} / \mathrm{L}$ were determined for the occurrence of $\mathrm{CK}$, metritis, DA, and lameness, respectively $(P<0.05$; Table 2$)$. The optimum BHBA threshold for the occurrence of mastitis was not significant $(>0.3 \mathrm{mmol} / \mathrm{L} ; P=0.65)$. Because RP and milk fever occur immediately after parturition, a BHBA threshold was not determined.

\section{Subclinical Ketosis}

Overall prevalence of SCK using a threshold $\geq 1.2$ $\mathrm{mmol} / \mathrm{L}$ of blood BHBA was 21.8\%. Maximum and minimum prevalence of SCK were 36.6 and $11.2 \%$ for Italy and Turkey, respectively (Table 1). Eight variables - country, months, milk yield (continuous variable), parity, RP, milk fever, mastitis, and metritis - were tested in univariate logistic models. Because milk yield $(P=0.53)$ did not meet the inclusion criteria $(P<0.10), 7$ variables were tested in a multivariate logistic regression. Only 5 variables were retained in the final logistic model $(P<0.05$; Table 3$)$. This model suggested that dairy cows suffering from RP and metritis were at risk for subsequent SCK [RP: odds ratio $(\mathbf{O R})=1.4,95 \% \mathrm{CI}: 1.2$ to 1.8 ; metritis: $\mathrm{OR}=1.7$, 95\% CI: 1.3 to 2.1 ; Table 3].

\section{Metritis}

An optimum threshold of $\geq 1.4 \mathrm{mmol} / \mathrm{L}$ of blood BHBA was determined with $28.5 \%$ sensitivity and $84.1 \%$ specificity $(\mathrm{AUC}=0.6 ; \mathrm{LR}+=1.8 ; P<0.001)$. Eight variables - country, month, milk yield, parity, RP, mastitis, BHBA threshold (below and above 1.4 $\mathrm{mmol} / \mathrm{L}$ ), and SCK - were tested in univariate logistic models. In the final multivariate logistic model, however, only 4 variables were retained $(P<0.05$; Table 4). The odds of having metritis were 2.5 (95\% CI: 1.9 to 3.1 ) and 1.7 (95\% CI: 1.4 to 2.1 ) greater in cows with RP and SCK, respectively (Table 4). Similar to the previous multivariate logistic model with optimal threshold (Table 4), the model including SCK indicated a 1.5 (95\% CI: 1.2 to 1.8$)$ times increased odds of having metritis $(P<0.001)$.

\section{Mastitis}

An optimum threshold of $\geq 0.3 \mathrm{mmol} / \mathrm{L}$ of blood BHBA was determined with $19.6 \%$ sensitivity and $84 \%$ specificity; however, the association was nonsignificant $(\mathrm{AUC}=0.5 ; \mathrm{LR}+=1.2 ; P=0.65)$. Eight variablescountry, months, milk yield, parity, RP, metritis, BHBA threshold (below and above $0.3 \mathrm{mmol} / \mathrm{L}$ ), and SCK - were tested in univariate logistic models. Because BHBA threshold $(\geq 0.3 \mathrm{mmol} / \mathrm{L} ; P=0.69)$ and SCK $(P=0.134)$ did not meet the inclusion criteria $(P<0.10)$, only 7 variables were tested in multivariate logistic regression. In the final multivariate logistic model, only 5 variables were retained $(P<0.05$; Table $5)$. The odds of having mastitis were 2.7 (95\% CI: 1.5 to $2.8 ; P<0.001)$ and 1.6 (95\% CI: 1.2 to $2.3 ; P=$ $0.002)$ greater in cows with RP and metritis, respectively (Table 5).

\section{Clinical Ketosis}

An optimum threshold $\geq 1.1 \mathrm{mmol} / \mathrm{L}$ of blood BHBA was determined with $81.2 \%$ sensitivity and $77.1 \%$ specificity $(\mathrm{AUC}=0.84 ; \mathrm{LR}+=3.5 ; P<0.001$; Table 2$)$ for the occurrence of CK. For predicting CK, 9 variablescountry, months, milk yield, parity, RP and mastitis, BHBA threshold (below and above $1.1 \mathrm{mmol} / \mathrm{L}$ ), metritis, and SCK - were tested in univariate logistic models. Only 5 variables were retained in the final logistic model $(P<0.001$; Table 6$)$. The odds of having CK were 2.1 (95\% CI: 1.4 to $3.1 ; P=0.0003)$ and 10.5 (95\% CI: 7.2 to $15.3 ; P<0.001)$ greater in cows with metritis and optimum threshold $\geq 1.1 \mathrm{mmol} / \mathrm{L}$, respectively (Table 6 ). The model also determined that multiparous cows ( $\geq 4$ parity) had greater odds for development of CK $(\mathrm{OR}=2.2,95 \% \mathrm{CI}: 1.4$ to $3.5 ; P<0.001)$ compared with cows of parity 1,2 , and 3 .

Similar to the previous multivariate binary logistic model with optimal threshold (Table 6), a model including SCK demonstrated 9.5 (95\% CI: 6.7 to 13.5) times increased odds for subsequently developing CK $(P<0.001)$. 
Table 2. Evaluation of the risk of metritis, clinical ketosis, displaced abomasum, and lameness and univariate association with serum BHBA obtained during 2 to 15 DIM after calving in 5,884 dairy cows of 528 herds in 10 European countries

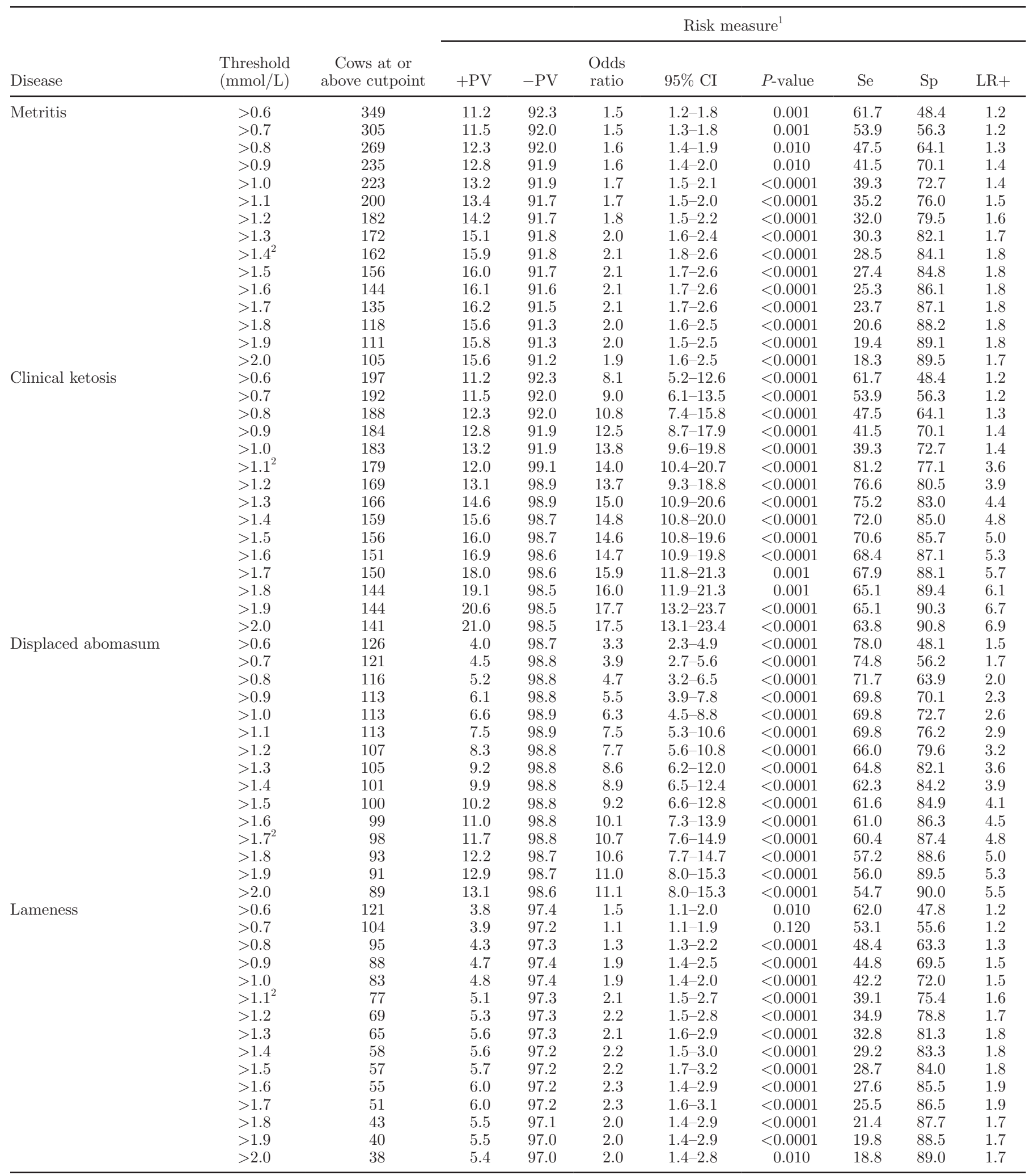

${ }^{1}+\mathrm{PV}=$ positive predictive value; $-\mathrm{PV}=$ negative predictive value; $\mathrm{Se}=$ sensitivity; $\mathrm{Sp}=$ specificity; $+\mathrm{LR}=$ positive likelihood ratio.

${ }^{2}$ Calculated optimal thresholds for each disease $(\mathrm{mmol} / \mathrm{L})$. 
Table 3. Results of multivariate analysis for the identification of risk factors for the development of subclinical ketosis (i.e., cows with blood BHBA $\geq 1.2 \mathrm{mmol} / \mathrm{L}$ ) in 5,041 dairy cows in 10 European countries

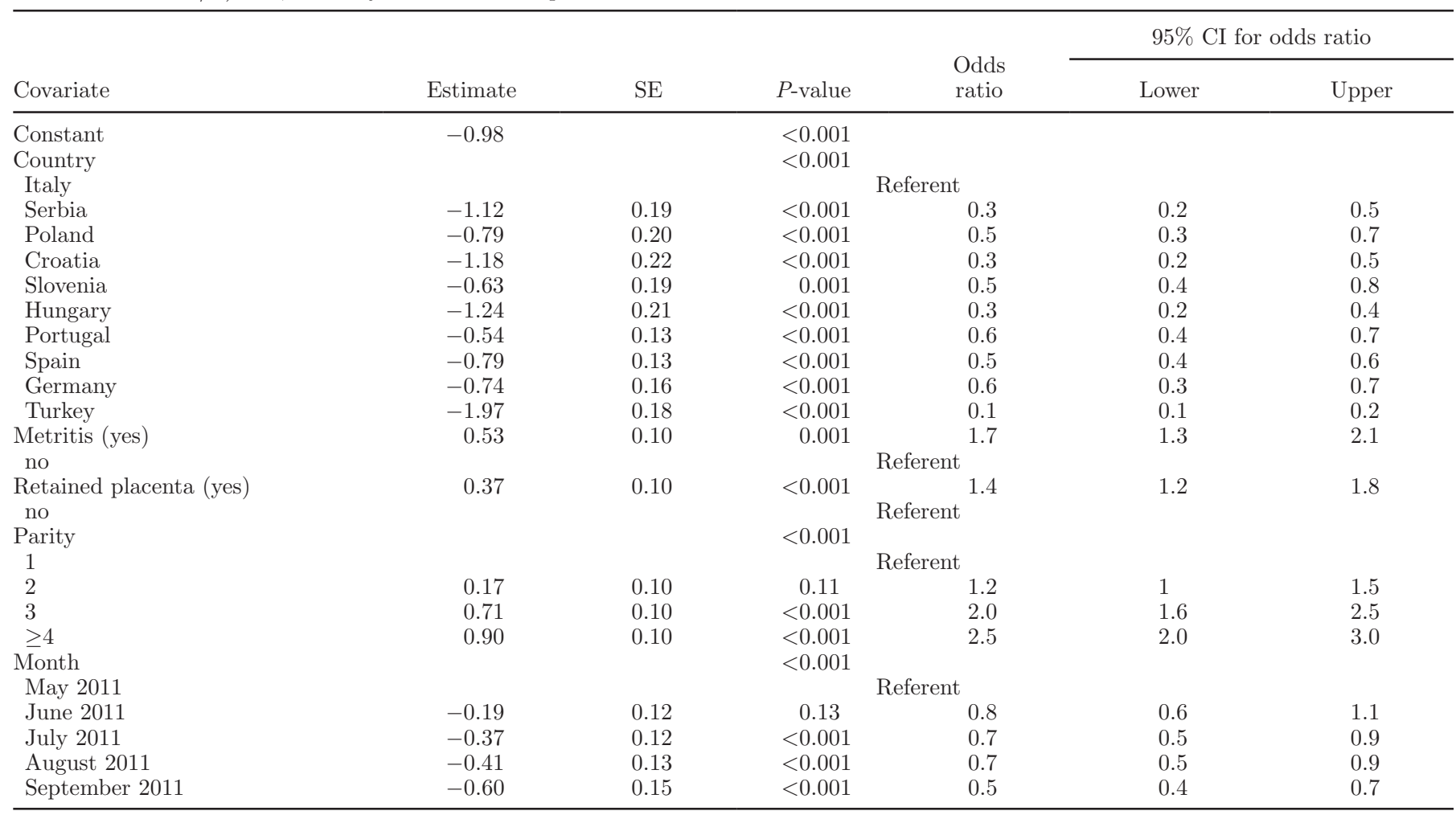

\section{Lameness}

An optimum threshold of $\geq 1.1 \mathrm{mmol} / \mathrm{L}$ of blood BHBA was determined with $39.1 \%$ sensitivity and $75.4 \%$ specificity $(\mathrm{AUC}=0.6 ; \mathrm{LR}+=1.6 ; P<0.001)$ for the occurrence of postpartum lameness. For predict- ing lameness, 9 variables - country, month, milk yield, parity, RP, mastitis, BHBA threshold (below and above $1.1 \mathrm{mmol} / \mathrm{L}$ ), metritis, and SCK - were tested in univariate logistic models. Milk fever was not associated with the occurrence of lameness, $(P=0.395)$ leaving 7 covariates for multivariate logistic model. Only 4

Table 4. Results of multivariate analysis for the identification of risk factors for the development of metritis in 5,037 dairy cows in 10 European countries

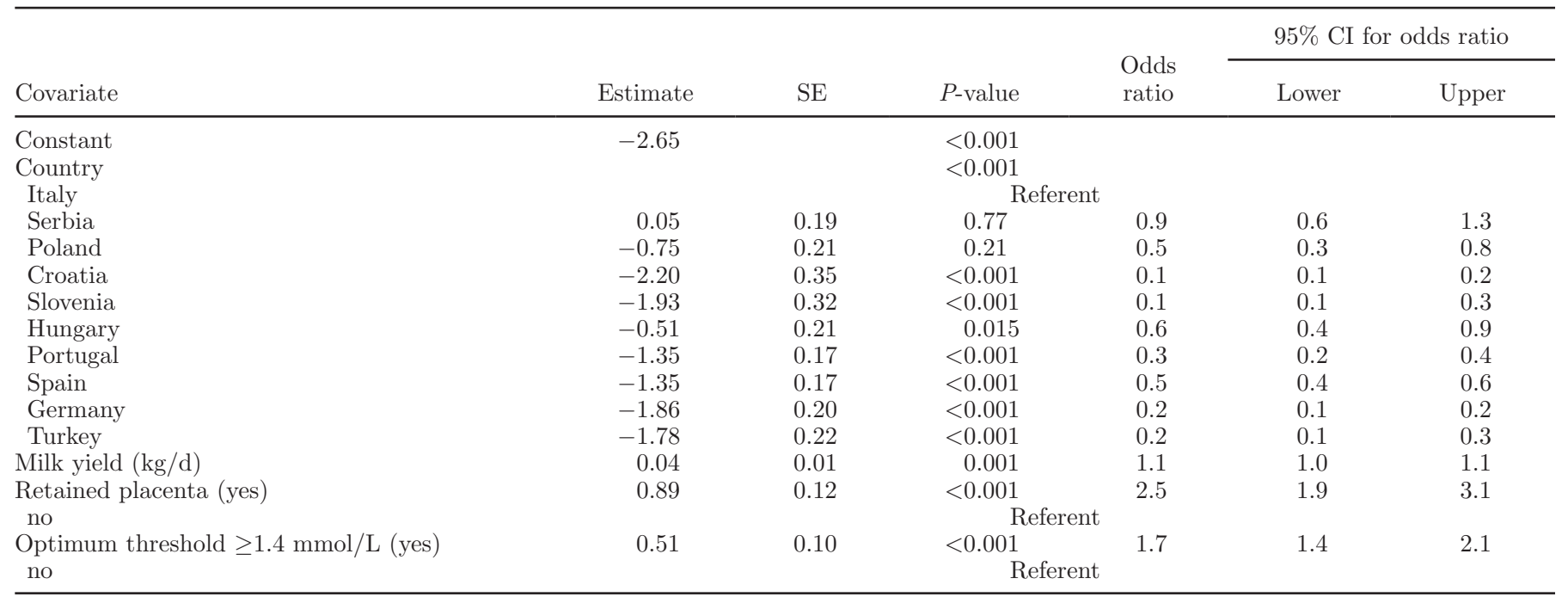


Table 5. Results of multivariate analysis for the identification of risk factors for the development of mastitis in 5,041 dairy cows in 10 European countries

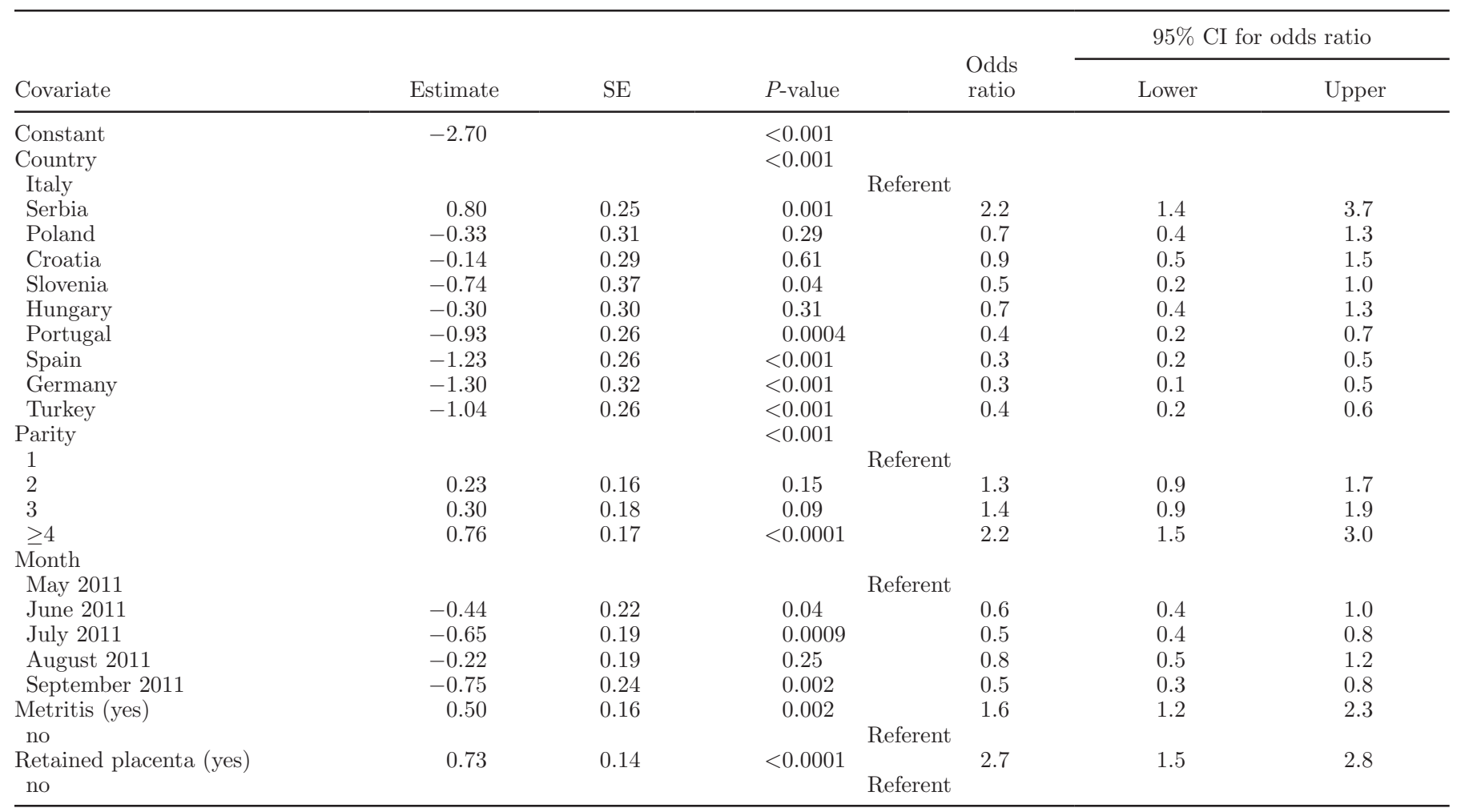

variables were retained in the final logistic model $(P<$ 0.001; Table 7). The odds of having lameness were 1.5 $(95 \%$ CI 1.0 to $2.2, P<0.001)$ and $1.8(95 \%$ CI 1.3 to $2.5, P<0.001)$ greater in cows with RP and BHBA levels above or at $1.1 \mathrm{mmol} / \mathrm{L}$, respectively (Table 7 ).

Similar to the previous multivariate binary logistic model with optimal threshold (Table 7), the model including SCK demonstrated 1.8 (95\% CI 1.3 to 2.5) times increased odds for subsequent occurrence of lameness $(P<0.001)$.

\section{Displaced Abomasum}

An optimum threshold of $\geq 1.7 \mathrm{mmol} / \mathrm{L}$ of blood BHBA was determined with $60.4 \%$ sensitivity and $87.4 \%$ specificity $(\mathrm{AUC}=0.76 ; \mathrm{LR}+=4.8 ; P<0.001)$ for the occurrence of DA. For predicting DA, 12 factors - country, month, milk yield, parity, RP, milk fever, mastitis, BHBA threshold (below and above $1.7 \mathrm{mmol} / \mathrm{L}$ ), metritis, lameness, SCK, and CK-were tested in univariate logistic models. Plausible factors such as milk fever $(P=0.29)$ and lameness $(P=0.7)$ did not have any influence on the occurrence of DA. Therefore, 8 plausible factors remained and were tested in the multivariate logistic model. Only 4 variables were retained in the final logistic model $(P<0.001$;
Table 8). The odds of having DA were 6.9 (95\% CI: 4.9 to $9.9 ; P<0.001)$ greater in cows with a blood BHBA concentration of $\geq 1.7 \mathrm{mmol} / \mathrm{L}$ (Table 8).

Similar to the previous multivariate binary logistic model with optimal threshold (Table 8), the model including SCK demonstrated 5.0 (95\% CI: 3.5 to 7.2) times increased odds of subsequent occurrence of DA $(P<0.001)$. Moreover, this model in which $\mathrm{CK}$ was retained $(P<0.004)$ demonstrated $1.9(95 \%$ CI: 1.2 to 33.1) times increased odds of subsequently developing DA.

\section{DISCUSSION}

The objectives of this study were to (1) determine prevalence of SCK, (2) identify optimum thresholds of blood BHBA measured 2 to 15 DIM, and (3) study their relationships with postpartum-related diseases such as metritis, mastitis, CK, DA, and lameness in European dairy farms. In this large-scale, multi-regional, observational study, 5,884 cows of 528 herds from 10 European countries were analyzed. Differences in natural resources, cultural traditions, dairy farm structures, and market, have caused different regions in the European countries to implement different management systems (Hemme, 2007). Since 1984, 16 prevalence studies have 
Table 6. Results of multivariate analysis for the identification of risk factors for the development of clinical ketosis in 5,023 dairy cows in 10 European countries

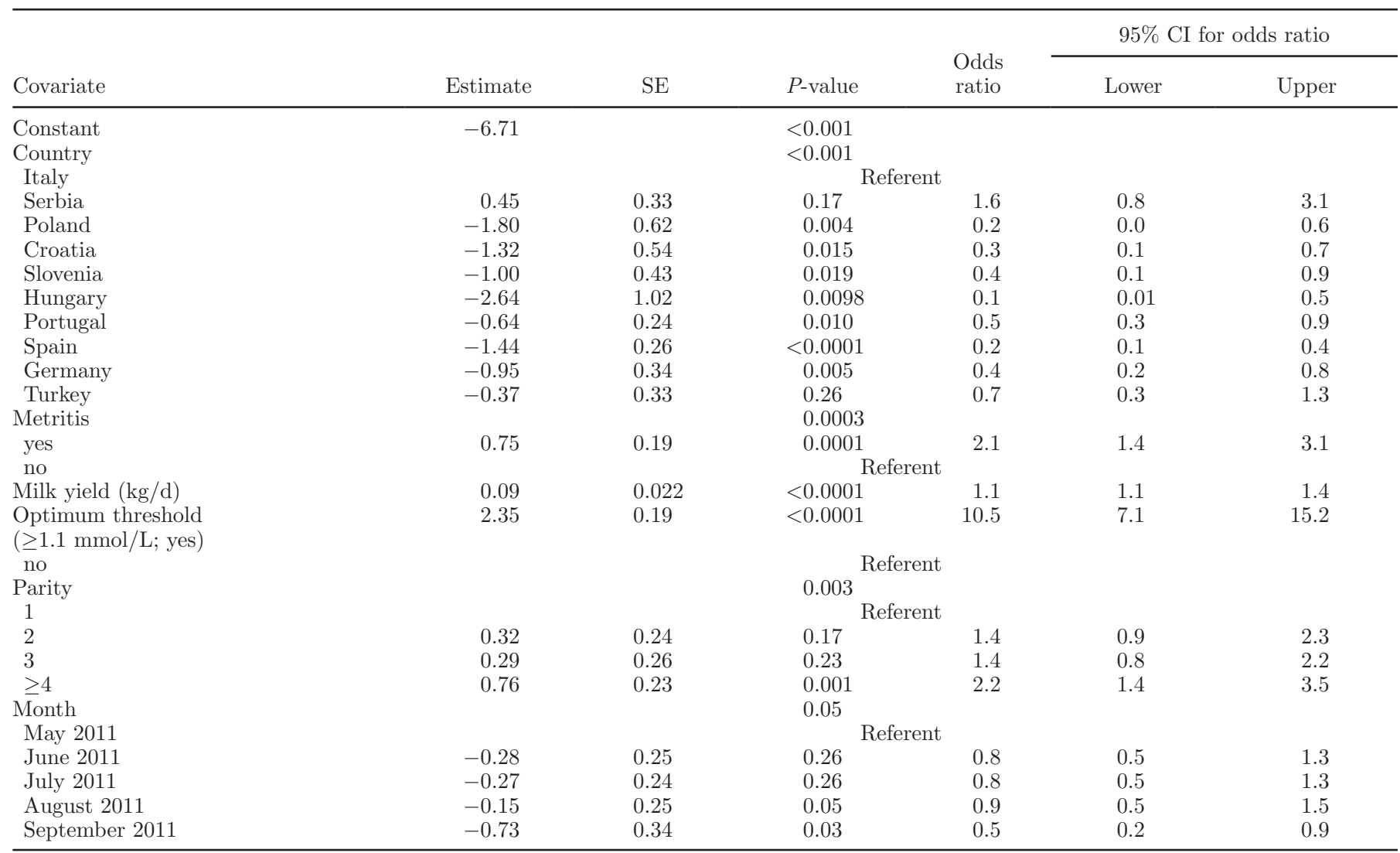

Table 7. Results of multivariate analysis for the identification of risk factors for the development of lameness in 5,041 dairy cows in 10 European countries

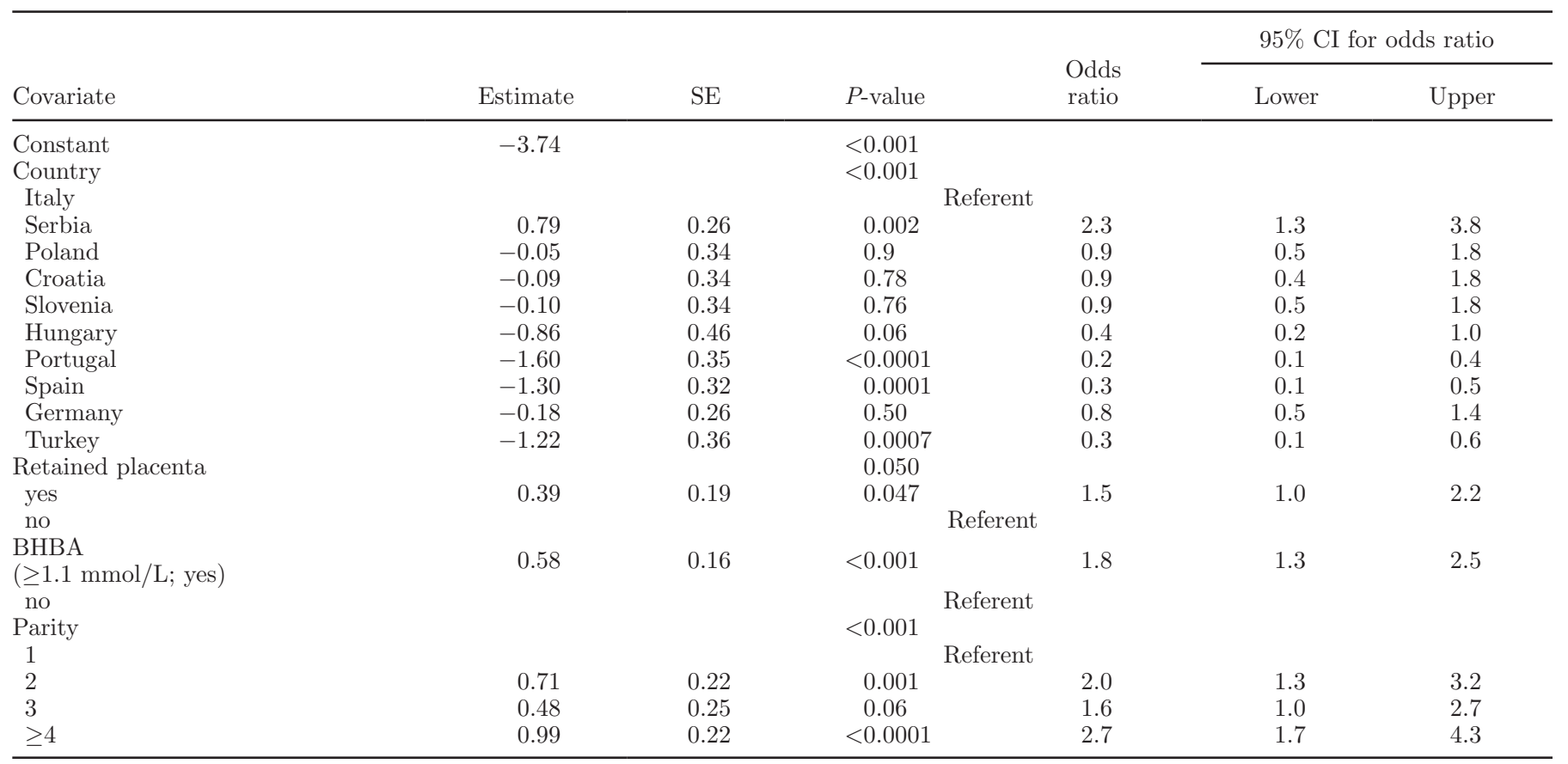


Table 8. Results of multivariate analysis for the identification of risk factors for the development of displaced abomasum in 5,412 dairy cows in 10 European countries

\begin{tabular}{|c|c|c|c|c|c|c|}
\hline Covariate & Estimate & $\mathrm{SE}$ & $P$-value & $\begin{array}{l}\text { Odds } \\
\text { ratio }\end{array}$ & \multicolumn{2}{|c|}{$95 \%$ CI for odds ratio } \\
\hline Italy & \multicolumn{6}{|c|}{ Referent } \\
\hline Serbia & -0.89 & 0.45 & 0.05 & 0.4 & 0.2 & 1.0 \\
\hline Poland & -0.53 & 0.46 & 0.25 & 0.6 & 0.2 & 1.5 \\
\hline Hungary & -1.26 & 0.50 & 0.01 & 0.3 & 0.1 & 0.8 \\
\hline Portugal & -0.53 & 0.25 & 0.036 & 0.6 & 0.4 & 1.0 \\
\hline Spain & -0.91 & 0.26 & 0.0006 & 0.4 & 0.3 & 0.7 \\
\hline Germany & -1.14 & 0.45 & 0.011 & 0.3 & 0.1 & 0.8 \\
\hline Turkey & -1.43 & 0.41 & 0.0005 & 0.2 & 0.1 & 0.5 \\
\hline Month & & & 0.01 & & & \\
\hline May 2011 & \multicolumn{6}{|c|}{ Referent } \\
\hline no & \multicolumn{6}{|c|}{ Referent } \\
\hline Parity & & & $<0.001$ & & & \\
\hline 1 & \multicolumn{6}{|c|}{ Referent } \\
\hline 2 & 0.18 & 0.27 & 0.4 & 1.2 & 0.7 & 2.1 \\
\hline 3 & 0.63 & 0.26 & 0.01 & 1.9 & 1.1 & 3.1 \\
\hline$\geq 4$ & 0.46 & 0.26 & 0.07 & 1.6 & 1.0 & 2.7 \\
\hline
\end{tabular}

demonstrated that measuring BHBA in blood $(\mathrm{n}=1)$, serum $(\mathrm{n}=13)$, and milk $(\mathrm{n}=2)$ early postpartum is associated with other postpartum diseases. Most of these studies collected data from dairy herds within a $20-$ to $30-\mathrm{km}$ radius of a particular region (LeBlanc et al., 2005; Duffield et al., 2009) or were limited to 3 or 4 neighboring states of the United States (Ospina et al., 2010). Only one study (Chapinal et al., 2011) demonstrated relationships between concentrations of energy metabolites in the periparturient period and postpartum diseases based on diverse geographical areas within North America. A multi-regional study encompassing multiple European states investigating prevalence of SCK and relationships between blood BHBA concentrations early postpartum and postpartum diseases has not yet been conducted. This study provides new insights into on-farm blood BHBA concentrations between 2 and $15 \mathrm{~d}$ postpartum and risk factors for diseases such as metritis, CK, lameness, and DA.

A recent study that empirically examined a wide range of possible cut-off values for BHBA concentration reported that during the first 2 wk after calving, a blood BHBA concentration of $\geq 1.2 \mathrm{mmol} / \mathrm{L}$ was the optimum cutpoint for predicting an increased likelihood of adverse health outcomes (Duffield et al., 2009). In the second week after calving, the BHBA cutpoint on the odds of DA was $\geq 1.8 \mathrm{mmol} / \mathrm{L}(\mathrm{OR}=6.22)$. The critical thresholds for BHBA determined in this study $(\mathrm{CK} \geq 1.1, \mathrm{DA} \geq 1.7$, metritis $\geq 1.4$, lameness $\geq 1.1$ $\mathrm{mmol} / \mathrm{L}$ ) were similar to the above range. Furthermore, our data support previous reports on associations between SCK during the first 15 DIM and metritis, CK, and DA (LeBlanc et al., 2005; Duffield et al., 2009).

Incidence rates of RP and milk fever in our data set were in accordance with previous studies (Dohoo and Martin, 1984; LeBlanc et al., 2005; Duffield et al., 2009). Because cases of RP or milk fever occurred within 24 to $72 \mathrm{~h}$ (LeBlanc et al., 2005; Cook et al., 2006; Duffield et al., 2009) after parturition, their associations with blood BHBA were not evaluated. Because both diseases have been demonstrated to be potential risk factors for postpartum diseases, we did evaluate their associations with the 6 postpartum diseases of interest. As previously shown, this study suggests that multiparous cows have 2.4 (95\% CI: 1.8 to 3.1 ) and 2.5 (95\% CI: 1.4 to 4.3) times greater odds for RP and milk fever, respectively, compared with primiparous cows (Dohoo and Martin, 1984; LeBlanc et al., 2005; Duffield et al., 2009).

The finding of elevated ketone bodies and subsequent risk of CK is supported by other studies (Dohoo and Martin, 1984; Duffield et al., 2009). The optimum BHBA cutpoint based on the maximum total sensitivity and specificity for CK in this study $(\geq 1.1 \mathrm{mmol} / \mathrm{L})$ 
was greater than $1.0 \mathrm{mmol} / \mathrm{L}$ serum BHBA (Ospina et al., 2010) and lower than in previous reports $(\geq 1.2$ to $\geq 1.4 \mathrm{mmol} / \mathrm{L}$; Duffield et al., 2009; Seifi et al., 2011). However, the reported sensitivity and specificity for the identification of an optimum BHBA cutpoint for CK was greater in this study (sensitivity $81.2 \%$, specificity $77.1 \%$ ) compared with previous studies (Duffield et al., 2009: first week postpartum: sensitivity $43.7 \%$, specificity $76.6 \%$, and second week postpartum: sensitivity 45.0\%, specificity 88.4\%; Ospina et al., 2010: 3 to 15 DIM sensitivity $57.0 \%$, specificity $80.0 \%$; Seifi et al., 2011: first week postpartum: sensitivity $67.7 \%$, specificity $82.2 \%)$. Furthermore, the LR+ calculated in this study (4.8) for having CK was greater than in previous studies (2.75 to 3.14; Duffield et al., 2009; Ospina et al., 2010).

The optimum cutpoint of blood BHBA in this study for predicting DA was greater than the $\geq 0.9$ to $\geq 1.4$ mmol/L serum BHBA (LeBlanc et al., 2005; Chapinal et al., 2011; Seifi et al., 2011) and lower than $\geq 1.8$ mmol/L serum BHBA (Duffield et al., 2009). Overall, however, our data support evidence of previous reports on the association of postpartum BHBA concentrations with DA. In the above mentioned studies the odds of having DA were 2.9 to 13.6 times greater than in cows with BHBA concentrations below the cutpoints. Our data generated from 10 European countries with diverse management systems and rations confirm these odds ratios. In this study, cows with BHBA $\geq 1.2$ or $\geq 1.4 \mathrm{mmol} / \mathrm{L}$ in the first 15 DIM had 7.8 (95\% CI: 5.5 to 10.8 ) to 8.9 (95\% CI: 6.4 to 12.4 ) times greater odds of having a case of DA than cows with BHBA below the cutpoints. The sensitivity and specificity of an optimum BHBA cutpoint of our study is in accordance of past 5 studies (i.e., LeBlanc et al., 2005; Duffield et al., 2009; Ospina et al., 2010; Chapinal et al., 2011; Seifi et al., 2011). In these studies, the reported sensitivity and specificity of an optimum BHBA cutpoint (measured during the first 2 wk postpartum) for identification of DA were 43.7 to $71 \%$ and 69 to $88.4 \%$, respectively.

An increase in BHBA and metritis in this study was in accordance with previous studies conducted in North America (Dohoo and Martin, 1984; Duffield et al., 2009). Such an association between SCK and metritis could be due to decreased DMI 1 to 2 wk prepartum (Huzzey et al., 2007), increased NEFA pre- and postpartum (Duffield et al., 2009; Ospina et al., 2010; Chapinal et al., 2011), and subsequent postpartum increase of BHBA (LeBlanc et al., 2005; Duffield et al., 2009; Chapinal et al., 2011), which has been shown to be a risk factor for the occurrence of metritis postpartum. Low availability of glucose and increased NEFA and BHBA concentrations have been shown to impair several pathways of immune defense in several studies
(Hammon et al., 2006; Scalia et al., 2006; Graugnard et al., 2012). Hammon et al. (2006) reported that cows that went on to develop puerperal metritis had a greater degree of immunosuppression relative to healthy cows as measured by neutrophil function.

The documented prevalence of metritis from studies conducted in North America and irrespective of parity varies widely, from 0.7\% (Bruun et al., 2002), 2.1\% (Markusfeld et al., 1997), 2.7\% (Duffield et al., 2009), $7 \%$ (Ospina et al., 2010), 21.7\% (Hammon et al., 2006 ), $16.7 \%$ (6.5 to $35.7 \%$ depending on the region; Chapinal et al., 2011) to $69 \%$ (Urton et al., 2005). In our study, reported prevalence by country varied from $3.2 \%$ (Croatia) to $24.9 \%$ (Italy). We tried to minimize erroneous recording of metritis by providing a list with disease definitions to the veterinarians. According to Sheldon et al. (2006) and similar to the study conducted by Duffield et al. (1998), metritis was defined as veterinary diagnosis based on systemic illness (fever and inappetence, with or without signs of cardiovascular compromise) attributable to fetid uterine infection before 15 DIM. Poor sensitivity and moderate specificity of the blood BHBA threshold $\geq 1.4 \mathrm{mmol} / \mathrm{L}$ for predicting metritis in this study is in accordance with previous studies (sensitivity 28.3 to $63 \%$ and specificity 48 to $83.7 \%$; Duffield et al., 2009; Dubuc et al., 2010; Ospina et al., 2010).

An association between SCK (2 to 15 DIM) and clinical mastitis (within 30 DIM) postpartum was not revealed in our data set. Similarly, Duffield et al. (2009) failed to demonstrate an association between incidence of clinical mastitis postpartum and BHBA measured during the first 2 wk after calving. The recording of clinical mastitis may have influenced the association with BHBA concentrations measured at 2 to 15 DIM. Therefore, we evaluated the association of blood BHBA concentration and SCK during 2 to 7 DIM and 8 to 15 DIM, respectively, with the subsequent occurrence of clinical mastitis. However, an association between blood BHBA concentration or SCK during 2 to 7 DIM (BHBA concentration: $P=0.731$; SCK: $P=0.20$ ) and 8 to 15 DIM (BHBA concentration: $P=0.99$; SCK: $P$ $=0.587)$ with clinical mastitis did not exist. Clinical ketosis and DA were recorded during the same period and were associated with elevated BHBA. The possible explanation for this difference might be that CK and DA are metabolic disorders and have a direct relationship with NEB (Drackley, 1999). The incidence of clinical mastitis is more influenced by environmental and sanitary conditions of the farm (Ruegg, 2003; Kahn and Line, 2010). It is well documented that NEB leads to immunosuppression and increases susceptibility to clinical mastitis (Drackley, 1999). Suriyasathaporn et al. (2000) and LeBlanc (2010) reported that SCK in 
the first 2 wk did not have an association with the incidence of clinical mastitis; however, it increased severity and duration of clinical mastitis. The latter was not the scope of this study. We hypothesize that the result of this study might have been influenced by the diversity of the dairy farms, diagnoses from multiple investigators, environmental conditions, and frequency, timing, and method of milking.

Our data demonstrate that the incidence of postpartum lameness varies from 1.2 to $10.4 \%$ (average $3.2 \%$ ) in European dairy herds. This incidence estimate is lower than the incidence range of 7 to $34 \%$ reported in the past (Alban, 1995; Clarkson et al., 1996; Bicalho et al., 2008). It is well documented that lameness prevalence appears to be affected by several factors such as free stall facilities, herd size, regrouping, concrete floor, season and regions of cows (Barker et al., 2007, 2010). The scope of this article was to evaluate relationships of BHBA within 2 to 15 DIM with the occurrence of postpartum diseases. Therefore, we did not look at the above-mentioned plausible factors. In this study, we used the definition of lameness as previously described (Cook et al., 2006) as "producer diagnosis of undifferentiated lameness within 30 DIM based on an abnormal gait or lack of weight bearing on a limb; includes diagnoses of interdigital and digital dermatitis." We are aware that this definition is broad and does not consider the multitude of pathogenetic factors. Because of the size of the study, a consistent implementation of a gait score (Sprecher et al., 1997) was not feasible. It is likely that using a more elaborate diagnostic approach would have affected the reported incidence. Nevertheless, to the best of our knowledge this is the first large data set that has demonstrated that cows with greater blood BHBA concentrations during 2 to 15 DIM have an increased odds for lameness. Unfortunately, the association and pathways between higher BHBA concentrations and lameness remain speculative. Our data also show a relatively low sensitivity and moderate specificity of the BHBA threshold for lameness. This might be due to the broad definition of lameness (Cook et al., 2006) chosen and the multifactorial nature of the disease (Barker et al., 2007, 2010). Both factors may have influenced the test characteristics. Our study results also support earlier findings from a convenience sample of 57 (17 primiparous and 40 multiparous) cows from 1 farm (Calderon and Cook, 2011). Interestingly, lame cows had higher BHBA concentrations $(1.165 \mathrm{mmol} / \mathrm{L})$ than nonlame cows $(0.687 \mathrm{mmol} / \mathrm{L}$; $P<0.001)$. Whether lame cows frequented the feed bunk less often and consumed less feed and thus were at higher risk for SCK or whether SCK was part of the etiology of lameness remains speculative. These findings warrant further studies to investigate the relationship between elevated BHBA concentrations and lameness in dairy cows.

Subclinical ketosis early postpartum is a threshold disease (Oetzel, 2004) and has significant associations with metabolic diseases when BHBA concentrations are $\geq 1.2 \mathrm{mmol} / \mathrm{L}$ (Rollin et al., 2010). Interestingly, Oetzel (2004) evaluated data from a large field study in which BHBA was measured once weekly in early lactation cows (Duffield et al., 1998) and determined that the cumulative incidence of SCK was about 2.2 times greater than the average prevalence. This suggests that the incidence of ketosis in our study herds was greater than $21.8 \%$ and could have been up to almost $50 \%$. Furthermore, McArt et al. (2012) extrapolated from their study that a cow with a blood BHBA concentration at the high end of SCK range $(2.4 \mathrm{mmol} / \mathrm{L})$ is 3 times more likely to develop a DA and >50 times more likely to be removed from the herd.

Overall, odds ratios based on optimal disease-specific thresholds of BHBA did not change much when the thresholds were slightly varied. Furthermore, the odds ratios based on optimal disease-specific thresholds did not change much compared with a single threshold of $\geq 1.2 \mathrm{mmol} / \mathrm{L}$. These findings support the recommendation of a universal BHBA threshold (i.e., $1.2 \mathrm{mmol} / \mathrm{L}$ ) for herd evaluations.

For logistical reasons, farm-specific information on management and feeding practices was not collected. Nevertheless, we speculate that those practices were more diverse, based on the agricultural structure (Hemme, 2007), than in the sites enrolled in the North American studies and that these associations are not only prevalent for specific systems but are inherent in the dairy industry. All participating veterinarians and farmers in this study were educated about each disease definition with an information sheet providing definitions for metritis, mastitis, CK, and DA (Duffield et al., 1999; LeBlanc et al., 2002) and lameness (Cook et al., 2006). Nevertheless, participation of multiple investigators, a study design component unavoidable for large field trials, and inter-clinician variability might have biased the results on associations between elevated levels of BHBA and disease occurrence and statistical relevance for potential interactions in the final multivariate models despite these efforts. Several factors might have affected the incidence rates of the reported diseases. First, accuracy of diagnoses might be different between the diseases. We speculate that the diagnosis of DA is more specific than that of lameness. It has been shown that the mean prevalence of clinical lameness scored by an independent investigator was $24.6 \%$, which was 3.1 times greater than the prevalence estimated by the herd managers (Espejo et al., 2006). Second, one has to keep in mind that the 
accuracy of implementation of a disease definition and the intensity of disease monitoring and documenting inherently influence incidence rates. These unavoidable factors might have confounded our results as well as previous results.

\section{CONCLUSIONS}

Prevalence of SCK (blood BHBA $\geq 1.2 \mathrm{mmol} / \mathrm{L}$ ) is high between 2 and 15 DIM in 10 European countries. Elevated BHBA concentrations measured with a handheld electronic meter on farm within 2 to 15 DIM after calving are associated with an increased odds of metritis, clinical ketosis, lameness, and displaced abomasum. Odds ratios were highest at disease-specific BHBA thresholds for metritis, CK, DA, and lameness. However, odds ratios do not change much when a uniform threshold of $\geq 1.2 \mathrm{mmol} / \mathrm{L}$ blood BHBA is used. Although relevant for research purposes, it is not necessary to use disease-specific thresholds in practice.

\section{ACKNOWLEDGMENTS}

We are grateful to all veterinarians and farmers for participating in this study and Bayer Health Care (Leverkusen, Germany) for financial and scientific support.

\section{REFERENCES}

Alban, L. 1995. Lameness in Danish dairy cows: Frequency and possible risk factors. Prev. Vet. Med. 22:213-225.

Barker, Z. E., J. R. Amory, J. L. Wright, R. W. Blowey, and L. E. Green. 2007. Management factors associated with impaired locomotion in dairy cows in England and Wales. J. Dairy Sci. 90:3270-3277.

Barker, Z. E., K. A. Leach, H. R. Whay, N. J. Bell, and D. C. J. Main. 2010. Assessment of lameness prevalence and associated risk factors in dairy herds in England and Wales. J. Dairy Sci. 93:932-941.

Bicalho, R. C., L. D. Warnick, and C. L. Guard. 2008. Strategies to analyze milk losses caused by diseases with potential incidence throughout the lactation: A lameness example. J. Dairy Sci. 91:2653-2661.

Borchardt, S., and R. Staufenbiel. 2012. Evaluation of the use of nonesterified fatty acids and $\beta$-hydroxybutyrate concentrations in pooled serum samples for herd-based detection of subclinical ketosis in dairy cows during the first week after parturition. J. Am. Vet. Med. Assoc. 240:1003-1011.

Bruun, J., A. K. Ersbøll, and L. Alban. 2002. Risk factors for metritis in Danish dairy cows. Prev. Vet. Med. 54:179-190.

Calderon, D. F., and N. B. Cook. 2011. The effect of lameness on the resting behavior and metabolic status of dairy cattle during the transition period in a freestall-housed dairy herd. J. Dairy Sci. 94:2883-2894.

Chapinal, N., M. Carson, T. F. Duffield, M. Capel, S. Godden, M. Overton, J. E. P. Santos, and S. J. LeBlanc. 2011. The association of serum metabolites with clinical disease during the transition period. J. Dairy Sci. 94:4897-4903.

Chapinal, N., M. E. Carson, S. J. LeBlanc, K. E. Leslie, S. Godden, M. Capel, J. E. P. Santos, M. W. Overton, and T. F. Duffield. 2012. The association of serum metabolites in the transition period with milk production and early-lactation reproductive performance. J. Dairy Sci. 95:1301-1309.

Clarkson, M. J., D. Y. Downham, W. B. Faull, J. W. Hughes, F. J. Manson, J. B. Merritt, R. D. Murray, W. B. Russell, J. E. Sutherst, and W. R. Ward. 1996. Incidence and prevalence of lameness in dairy cattle. Vet. Rec. 138:563-567.

Cook, N., G. Oetzel, and K. Nordlund. 2006. Modern techniques for monitoring high- producing dairy cows 1 . Principles of herd-level diagnoses. In Pract. 28:510-515.

Dohoo, I. R., and S. W. Martin. 1984. Disease, production and culling in Holstein-Friesian cows III. Disease and production as determinants of disease. Prev. Vet. Med. 2:671-690.

Dohoo, I. R., W. Martin, and H. Stryhn. 2009. Veterinary Epidemiologic Research. 2nd ed. AVC Inc., Charlottetown, PEI, Canada.

Dohoo, I. R., S. Wayne Martin, A. H. Meek, and W. C. D. Sandals. 1983. Disease, production and culling in Holstein-Friesian cows. I. The data. Prev. Vet. Med. 1:321-334.

Drackley, J. K. 1999. Biology of dairy cows during the transition period: The final frontier? J. Dairy Sci. 82:2259-2273.

Dubuc, J., T. F. Duffield, K. E. Leslie, J. S. Walton, and S. J. LeBlanc. 2010. Risk factors for postpartum uterine diseases in dairy cows. J. Dairy Sci. 93:5764-5771.

Duffield, T. F., K. E. Leslie, D. Sandals, K. Lissemore, B. W. McBride, J. H. Lumsden, P. Dick, and R. Bagg. 1999. Effect of a monensincontrolled release capsule on cow health and reproductive performance. J. Dairy Sci. 82:2377-2384.

Duffield, T. F., K. D. Lissemore, B. W. McBride, and K. E. Leslie 2009. Impact of hyperketonemia in early lactation dairy cows on health and production. J. Dairy Sci. 92:571-580.

Duffield, T. F., D. Sandals, K. E. Leslie, K. Lissemore, B. W. McBride, J. H. Lumsden, P. Dick, and R. Bagg. 1998. Efficacy of monensin for the prevention of subclinical ketosis in lactating dairy cows. J. Dairy Sci. 81:2866-2873.

Espejo, L. A., M. I. Endres, and J. A. Salfer. 2006. Prevalence of lameness in high-producing Holstein cows housed in freestall barns in Minnesota. J. Dairy Sci. 89:3052-3058.

Geishauser, T., K. Leslie, D. Kelton, and T. Duffield. 1998. Evaluation of five cowside tests for use with milk to detect subclinical ketosis in dairy cows. J. Dairy Sci. 81:438-443.

Graugnard, D. E., M. Bionaz, E. Trevisi, K. M. Moyes, J. L. SalakJohnson, R. L. Wallace, J. K. Drackley, G. Bertoni, and J. J. Loor. 2012. Blood immunometabolic indices and polymorphonuclear neutrophil function in peripartum dairy cows are altered by level of dietary energy prepartum. J. Dairy Sci. 95:1749-1758.

Greiner, M., D. Pfeiffer, and R. D. Smith. 2000. Principles and practical application of the receiver-operating characteristic analysis for diagnostic tests. Prev. Vet. Med. 45:23-41.

Gumen, A., A. Keskin, G. Yilmazbas-Mecitoglu, E. Karakaya, and M. C. Wiltbank. 2011. Dry period management and optimization of postpartum reproductive management in dairy cattle. Reprod. Domest. Anim. 46:11-17.

Hammon, D. S., I. M. Evjen, T. R. Dhiman, J. P. Goff, and J. L. Walters. 2006. Neutrophil function and energy status in Holstein cows with uterine health disorders. Vet. Immunol. Immunopathol. 113:21-29.

Hemme, T., 2007. IFCN Dairy Report. International Farm Comparison Network (IFCN) Dairy Research Center, Kiel, Germany.

Hoeben, D., C. Burvenich, A.-M. Massart-Leën, M. Lenjou, G. Nijs, D. Van Bockstaele, and J.-F. Beckers. 1999. In vitro effect of ketone bodies, glucocorticosteroids and bovine pregnancy-associated glycoprotein on cultures of bone marrow progenitor cells of cows and calves. Vet. Immunol. Immunopathol. 68:229-240.

Huzzey, J. M., D. M. Veira, D. M. Weary, and M. A. G. von Keyserlingk. 2007. Prepartum behavior and dry matter intake identify dairy cows at risk for metritis. J. Dairy Sci. 90:3220-3233.

Iwersen, M., U. Falkenberg, R. Voigtsberger, D. Forderung, and W. Heuwieser. 2009. Evaluation of an electronic cowside test to detect subclinical ketosis in dairy cows. J. Dairy Sci. 92:2618-2624.

Kahn, C. M., and S. Line. 2010. The Merck Veterinary Manual. 10th ed. Merck Sharp \& Dohme Corp., a subsidiary of Merck \& Co. Inc., Whitehouse Station, NJ. 
LeBlanc, S. 2010. Monitoring metabolic health of dairy cattle in the transition period. J. Reprod. Dev. 56:S29-S35.

LeBlanc, S. J., T. F. Duffield, K. E. Leslie, K. G. Bateman, J. Ten Hag, J. S. Walton, and W. H. Johnson. 2002. The effect of prepartum injection of vitamin $\mathrm{E}$ on health in transition dairy cows. J. Dairy Sci. 85:1416-1426.

LeBlanc, S. J., K. E. Leslie, and T. F. Duffield. 2005. Metabolic predictors of displaced abomasum in dairy cattle. J. Dairy Sci. $88: 159-170$.

Markusfeld, O., N. Galon, and E. Ezra. 1997. Body condition score, health, yield and fertility in dairy cows. Vet. Rec. 141:67-72.

McArt, J. A. A., D. V. Nydam, and G. R. Oetzel. 2012. Epidemiology of subclinical ketosis in early lactation dairy cattle. J. Dairy Sci. 95:5056-5066

Oetzel, G. R. 2004. Monitoring and testing dairy herds for metabolic disease. Vet. Clin. North Am. Food Anim. Pract. 20:651-674.

Ospina, P. A., D. V. Nydam, T. Stokol, and T. R. Overton. 2010 Evaluation of nonesterified fatty acids and $\beta$-hydroxybutyrate in transition dairy cattle in the northeastern United States: Critical thresholds for prediction of clinical diseases. J. Dairy Sci. 93:546-554.

Roberts, T., N. Chapinal, S. J. LeBlanc, D. F. Kelton, J. Dubuc, and T. F. Duffield. 2012. Metabolic parameters in transition cows as indicators for early-lactation culling risk. J. Dairy Sci. 95:30573063 .

Rollin, E., R. D. Berghaus, P. Rapnicki, S. M. Godden, and M. W. Overton. 2010. The effect of injectable butaphosphan and cyanocobalamin on postpartum serum $\beta$-hydroxybutyrate, calcium, and phosphorus concentrations in dairy cattle. J. Dairy Sci. 93:978 987.

Ruegg, P. L. 2003. Investigation of mastitis problems on farms. Vet. Clin. North Am. Food Anim. Pract. 19:47-73.
Scalia, D., N. Lacetera, U. Bernabucci, K. Demeyere, L. Duchateau, and C. Burvenich. 2006. In vitro effects of nonesterified fatty acids on bovine neutrophils oxidative burst and viability. J. Dairy Sci. $89: 147-154$

Seifi, H. A., S. J. LeBlanc, K. E. Leslie, and T. F. Duffield. 2011. Metabolic predictors of post-partum disease and culling risk in dairy cattle. Vet. J. 188:216-220.

Sheldon, I. M., G. S. Lewis, S. LeBlanc, and R. O. Gilbert. 2006. Defining postpartum uterine disease in cattle. Theriogenology 65:1516-1530.

Sprecher, D. J., D. E. Hostetler, and J. B. Kaneene. 1997. A lameness scoring system that uses posture and gait to predict dairy cattle reproductive performance. Theriogenology 47:1179-1187.

Suriyasathaporn, W., A. J. J. M. Daemen, E. N. NoordhuizenStassen, S. J. Dieleman, M. Nielen, and Y. H. Schukken. 1999 $\beta$-Hydroxybutyrate levels in peripheral blood and ketone bodies supplemented in culture media affect the in vitro chemotaxis of bovine leukocytes. Vet. Immunol. Immunopathol. 68:177-186.

Suriyasathaporn, W., C. Heuer, E. N. Noordhuizen-Stassen, and Y. H. Schukken. 2000. Hyperketonemia and the impairment of udder defense: A review. Vet. Res. 31:397-412.

Swets, J. A. 1988. Measuring the accuracy of diagnostic systems. Science 240:1285-1293.

Urton, G., M. A. G. von Keyserlingk, and D. M. Weary. 2005. Feeding behavior identifies dairy cows at risk for metritis. J. Dairy Sci 88:2843-2849.

Walsh, R. B., J. S. Walton, D. F. Kelton, S. J. LeBlanc, K. E. Leslie, and T. F. Duffield. 2007. The effect of subclinical ketosis in early lactation on reproductive performance of postpartum dairy cows. J. Dairy Sci. 90:2788-2796.

Willer, H. 1982. Praktische Stichprobenplanung. VEB Gustav Fischer Verlag, Jena, Germany. 